\title{
ĐIỀU TRI CAN THIỆP DÒ ĐộNG TĨNH MẠCH MÀNG CỨNG NGOÀI XOANG HANG CÓ BẢO VÊ XOANG TĨNH MẠCH
}

Trần Anh Tuấn ${ }^{1}$

\section{TÓM TẮT}

Mục tiêu nghiên cứu: Nghiên cứu kết quả điều trị rò màng cứng nội sọ ngoài xoang hang bằng can thiệp có bảo vệ xoang tînh mạch. Đối tượng và phương pháp: Các bệnh nhân rò động tĩnh mạch màng cứng ngoài xoang hang, được điêu trị can thiệp đường động mạch với dung dịch Onyx, đồng thời có tiếp cận đường tĩnh mach đề luồn bóng bơn chèn bảo vệ xoang tĩnh mạch. Kết quả: với 15 bệnh nhân được điều trị, 13 bệnh nhân có 1 điểm do, 2 bệnh nhân có 2 điểm rò độc lập trong đó chủ yếu nhóm IIa, IIb, IIa $+b$, chiếm $94 \%$ theo phân loại Cognard. Đường tiếp cận động mạch chủ yếu là cuống màng não giữa ( $100 \%$ bênh nhân) và nhánh chẩm $(88,2 \%$ bênh nhân). Kết quả nút tắc hoàn toàn được 13 bệnh nhân $(86,7 \%)$ khỏi hoàn toàn triệu chứng 8 bệnh nhân $(53.3 \%)$, cải thiện 1 phần 4 bệnh nhân $(26,7 \%)$, có 4 trường hợp tai biến trong đó 1 trường hợp mRS 5 $(6,7 \%)$. Kết luận: Điều trị rò động tĩnh mạch màng cứng ngoài xoang hang với bóng chen bảo vệ xoang tĩnh mạch là hiệu quả và giảm thiều tối đa nguy cơ.

\section{SUMMARY \\ ENDOVASCULAR TREATMENT OF DURAL ARTERIOVENOUS FISTULAS OF THE CARVENOUS SINUSES USING TRANSARTERIAL INTERVENTION COMBINED WITH TRANSVENOUS BALLOON PROTECTION OF THE VENOUS SINUS}

Studying the results of treatment of intrathoracic epidural fistula by intervention with intravenous sinus ballon protection. Objects and methods: Patients with epidural fistula causes of veins outside the cavernous sinus, are treated by intervene the arteries with Onyx embolization, and also have access to the intravenous route, using to insert the balloon protect the sinuses. Results: With 15 patients have treated, 13 patients had 1 fistular route, 2 patients had 2 independent fistula route, of which mainly groups IIa, IIb, IIa $+b$, accounting for $94 \%$ according to Cognard classification. The main route of access to the artery is the middle meningeal ( $100 \%$ of patients) and the occipital branch (88.2\% of patients). As a result, the total occlusion in 13 patients, $(86.7 \%)$ no signs of symptoms in 8 patients $(53.3 \%)$, improved symtoms in 4 patients $(26.7 \%)$, there were 4 cases of internal complications. 1 case of mRS $5(6.7 \%)$.Conclusion: Treatment of periosteal epidural arterial fistula with a

${ }^{1}$ Trung tâm Điện quang, BV Bạch Mai Chịu trách nhiệm chính: Trân Anh Tuấn Email: Bs.trananhtuan@yahoo.com.vn Ngày nhận bài: 7.01.2021

Ngày phản biện khoa học: 8.3.2021

Ngày duyệt bài: 16.3.2021 balloon to protect the venous sinus is effective and minimizes the risk.

Keys words: dural arteriovenous fistula, embolization, balloon.

\section{I. ĐẶT VẤN ĐỀ}

Rò động tĩnh mạch màng cứng (RĐTMMC là bệnh lý với tổn thương phức tạp, có thể gây ra các triệu chứng như đau đâu, ù tai gây ảnh hưởng đến chất lượng cuộc sống, nă̆ng hơn có thể gây ra xuất huyết nội sọ hoặc các tổn thương thân kinh khu trú $(1,2,3)$.

Với sự ra đời của vật chất tắc mạch lỏng (Onyx, Squid...) và các cải tiến trong công nghệ vi ống thông, can thiệp theo đường động mạch trở thành lựa chọn ưu tiên so với đường tĩnh mạch, tuy nhiên phương pháp này vẫn còn một số nhược điểm khi vật liệu tắc mạch trào ngược vào động mạch lành, hoặc lan vào và gây tắc xoang tĩnh mạch dẫn lưu. Trên nguyên tắc, việc "loại bỏ" được hoàn toàn xoang tĩnh mạch tổn thương sẽ giúp gây tắc được dị dạng, nhưng đối với trường hợp các xoang này còn chức năng thì sẽ gây tăng đáng kể tỷ lệ tai biến kèm theo, bao gồm nhồi máu tĩnh mạch và xuất huyết nội sọ. Sự ra đời của thế hệ bóng mới (Copernic RC, hã̃ng Balt, Pháp), chiến lược điêuu trị gây tắc dị dạng theo đường động mạch kèm bơm bóng chẹn bảo vệ xoang tĩnh mạch có thể giúp giải quyết các vấn đề còn tồn tại này ${ }^{(3,4)}$

\section{II. ĐỐI TƯợNG VÀ PHƯƠNG PHÁP NGHIÊN CứU \\ 2.1. Đối tượng nghiên cứu}

- Bệnh nhân được chẩn đoán xác định rò động tĩnh mạch màng cứng nội sọ ngoài vùng xoang hang bằng chụp mạch số hóa xóa nền, có chỉ định điều trị

- Bệnh nhân được điều trị bằng can thiệp nội mạch theo đường động mạch, phối hợp bóng chẹn bảo vệ xoang tĩnh mạch.

2.2. Phương pháp nghiên cứu

Thiết kế nghiên cứu: nghiên cứu can thiệp không đối chứng tiến cứu, từ 1/2017 đến 8/2020.

Cõ mẫu nghiên cứu: cõ̃ mẫu thuận tiện.

Thực tế thu được 15 bệnh nhân

Phương tiện nghiên cứu: Máy chụp mạch DSA Philips Allura 3D

Quy trinh:

- Bênh nhân được gây tê tại chỗ

- Tiếp cận đường động mạch bằng sonde 6F, 
chọn lọc microcatheter vào cuống nuôi dị dạng, tiếp cận đường tĩnh mạch qua sonde $6 \mathrm{~F}$ để luồn, chẹn bóng bảo vệ tĩnh mạch

- Bơm vật liệu nút mạch (Onyx) qua đường động mạch trong khi bơm bóng chẹn căng đường tĩnh mạch cho tới khi hết dị dạng hoặc tắc tối đa

2.3. Đạo đức nghiên cứu. Nghiên cứu được triển khai và đã được Hội đồng Đạo đức trong nghiên cứu y sinh học của bệnh viện Bạch Mai thông qua.

Bênh nhân được giải thích đầy đủ, có quyền từ chối không tham gia vào nghiên cứu.

\section{KẾT QUẢ NGHIÊN CứU}

Có tất cả 15 bệnh nhân thỏa mãn tiêu chuẩn lựa chọn

3.1. Đặc điểm chung nhóm bệnh nhân nghiên cứu

3.1.1. Tuổi và giới. Trong tổng số 15 bệnh nhân, có 7 bệnh nhân nam (chiếm 46,7\%), 8 bệnh nhân nữ (chiếm 53,3\%). Nhóm tuổi >50 có 8 bệnh nhân, 30-50 tuổi có 5 bệnh nhân và nhóm <30 tuối có 2 bệnh nhân (13,3\%)

3.1.2. Triệu chứng lâm sàng bệnh nhân trước can thiệp

Bảng 3.1. Phân độ triệu chứng lâm sàng bệnh nhân trước can thiệp

\begin{tabular}{|c|c|c|}
\hline Dâu hiệu lâm sàng & $\begin{array}{c}\text { n (bệnh } \\
\text { nhânn) }\end{array}$ & $\begin{array}{c}\text { Tỷ lệ } \\
(\mathbf{\%})\end{array}$ \\
\hline Phát hiện tình cờ & 1 & 6,7 \\
\hline Triệu chứng nhẹ & 12 & 80 \\
\hline Triệu chứng nặng & 2 & 13,3 \\
\hline Tống & 15 & 100 \\
\hline
\end{tabular}

Nhân xét: $86,7 \%$ có biểu hiện thuộc nhóm triệu chứng nhe (đau đâu, ù tai, nghe thấy tiếng thổi, đau dây $V$, giảm cảm giác nửa mặt...). Có 2 bệnh nhân $(13,3 \%)$ có biểu hiện thuộc triệu chứng nặng (động kinh, yếu $1 \frac{1}{2}$ người).

3.2. Đặc điểm hình ảnh của RĐTMMC nội sọ ngoài vùng xoang hang trên chụp mạch số hóa xóa nền

3.2.1. Vị trí rò. Trong tổng số 15 bệnh nhân nghiên cứu, đa số các trường hợp chỉ có dị dạng ở 1 vị trí $(86,7 \%)$. Có 2 trường hợp $(13,3 \%)$ ghi nhận phối hợp rò ở nhiều vị trí khác nhau, cả hai đều có rò ở hội lưu chẩm,

Bảng 3.2. Phân loại RĐTMMC nội sọ ngoài vùng xoang hang theo vị trí

\begin{tabular}{|c|c|c|}
\hline Vị trí & n (dị dạng) & Tỷ lệ (\%) \\
\hline $\begin{array}{c}\text { Xoang ngang - } \\
\text { sigma }\end{array}$ & 13 & 76,5 \\
\hline Xoang dọc trên & 2 & 11,7 \\
\hline Hội lưu chấm & 2 & 11,7 \\
\hline
\end{tabular}

\begin{tabular}{|c|c|c|}
\hline Vị trí khác & 0 & 0 \\
\hline Tống & 17 & 100 \\
\hline
\end{tabular}

Nhận xét: RĐTMMC nội sọ ngoài vùng xoang hang trong nghiên cứu gặp nhiêuu nhất ở vùng xoang ngang - sigma (chiếm 76,5\%)

3.2.2. Phân loại dị dạng RĐTMMC nội sọ ngoài vùng xoang hang theo Cognard

Bảng 3.3. Phân loại RĐTMMC nội sọ ngoaii vùng xoang hang theo Cognard

\begin{tabular}{|c|c|c|}
\hline Phân loại & n (bệnh nhân) & Tỷ lệ (\%) \\
\hline I & 0 & 0 \\
\hline II a & 8 & 47 \\
\hline II b & 3 & 17,6 \\
\hline II a+b & 5 & 29,4 \\
\hline III & 0 & 0 \\
\hline IV & 1 & 5,9 \\
\hline V & 0 & 0 \\
\hline Tống & 17 & 100 \\
\hline
\end{tabular}

Nhận xét: Trong tổng số 15 bệnh nhân, có 17 dị dạng (2 bệnh nhân có dị dạng ở 2 vị trí), chủ yếu nhóm IIa, IIb và IIa $+b$

3.2.3. Đặc điểm động mạch nuôi RĐTMMC nội sọ ngoài vùng xoang hang

Có 14 bệnh nhân có dị dạng được cấp máu từ nhiều nguồn khác nhau $(93,3 \%)$, chỉ có 1 bênh nhân có dị dạng được cấp máu từ một cuống mạch nuôi duy nhất $(6,7 \%)$. Số cuống mạch nuôi trung bình trên một bệnh nhân là $3.42 \pm 1.35$, ít nhất là 1 cuống nuôi, nhiều nhất là 6 cuống.

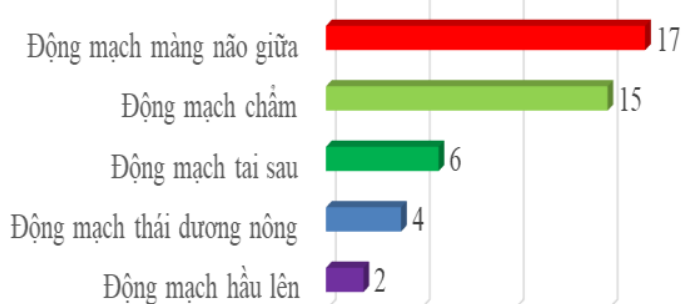

Biểu đồ 3.1. Số lượng dị dạng theo sự góp mặt các cuống nuôi từ động mạch cảnh ngoài

Nhận xét: Trong số những nhánh bên của động mạch cảnh ngoài, động mạch chẩm và động mạch màng não giữa có tỷ lệ cấp máu cho dị dạng cao nhất, lần lượt là $88,2 \%$ và $100 \%$,

3.3. Đánh giá quá trình can thiệp. Phần lớn các bệnh nhân chỉ phải can thiệp 1 lần (12/15), chiếm $80 \%$, có 3 bệnh nhân phải can thiệp 2 lần - chiếm $20 \%$, đây đều là các trường hợp dị dạng phức tạp, lan tỏa với nhiều cuống nuôi. 13/15 bệnh nhân được nút tắc hoàn toàn dị dạng sau can thiệp nội mạch, chiếm $86,7 \%$. Tỷ lệ nút tắc không hoàn toàn dị dạng là 13,3\%. 
3.3.1. Cuống mạch được can thiệp Bảng 3.4. Số cuống mạch được can thiệp

\begin{tabular}{|c|c|c|}
\hline $\begin{array}{c}\text { Cuống mach được } \\
\text { can thiệp }\end{array}$ & $\begin{array}{c}\mathbf{n} \text { (cuống } \\
\text { mạch) }\end{array}$ & $\begin{array}{c}\text { Tỷ lệ } \\
\text { \% }\end{array}$ \\
\hline $\begin{array}{c}\text { Động mạch màng } \\
\text { não giữa }\end{array}$ & 15 & 60 \\
\hline Động mạch chấm & 6 & 24 \\
\hline $\begin{array}{c}\text { Động mạch thái } \\
\text { dương nông }\end{array}$ & 2 & 8 \\
\hline Động mạch tai sau & 2 & 8 \\
\hline Động mạch hâuu lên & 0 & 0 \\
\hline Tống & 25 & 100 \\
\hline
\end{tabular}

Nhận xét: đường tiếp cập chính là đường động mạch màng não giữa

3.3.2. Tỷ lệ bảo tôn xoang khi dùng bóng chẹn tĩnh mạch

Bảng 3.5. Tỷ lệ bảo tồn xoang khi dùng bóng chen tĩnh mạch

\begin{tabular}{|c|c|c|}
\hline Mức độ bảo tồn & $\mathbf{n}$ (xoang) & Tỷ lệ (\%) \\
\hline Bảo tồn hoàn toàn & 15 & 83,3 \\
\hline Bảo tồn một phần & 2 & 11,1 \\
\hline Tắc xoang & 1 & 5,6 \\
\hline Tống & 18 & 100 \\
\hline
\end{tabular}

Nhận xét: Đa phần các trường hợp bao tồn được xoang $(94,4 \%)$

3.4. Đánh giá các tai biến của can thiệp Bảng 3.6. Các tai biến của can thiệp

\begin{tabular}{|c|c|c|}
\hline Tai biến & $\begin{array}{c}\mathbf{n} \text { (trường } \\
\text { hợp) }\end{array}$ & $\begin{array}{c}\text { Tỷ lệ } \\
(\mathbf{\%})\end{array}$ \\
\hline Tai biến không triệu chứng & 1 & 5,6 \\
\hline $\begin{array}{c}\text { Tai biến có triệu chứng } \\
\text { thoáng qua }\end{array}$ & 2 & 11,1 \\
\hline Tai biến có di chứng & 1 & 5,6 \\
\hline Tống & 4 & 22,2 \\
\hline
\end{tabular}

Nhận xét: Có 1 trường hợp tai biến nặng gây yếu liệt $(5,6 \%)$

3.5. Đánh giá lâm sàng sau can thiệp

Bảng 3.7. Mức độ cải thiện lâm sàng của bệnh nhân sau can thiệp

\begin{tabular}{|c|c|c|}
\hline $\begin{array}{c}\text { Mức độ cải thiện } \\
\text { lầm sàng }\end{array}$ & $\begin{array}{c}\text { n (bềnh } \\
\text { nhẩn) }\end{array}$ & $\begin{array}{c}\text { Tỷ lệ } \\
(\mathbf{\%})\end{array}$ \\
\hline Khỏi hoàn toàn & 8 & 53,3 \\
\hline Cải thiện một phần & 4 & 26,7 \\
\hline Không thay đối & 2 & 13,3 \\
\hline Nặng lên & 1 & 6,7 \\
\hline Tống & 15 & 100 \\
\hline
\end{tabular}

Nhận xét: Tỷ lệ khỏi hoàn toàn là 53,3\%, giảm nhe các triệu chứng so với trước can thiệp là $26,7 \%$, có 1 trường hợp $(6,7 \%)$ nặng hơn so với trước can thiệp.

\section{BÀN LUẬN}

4.1. Đặc điểm chung của nhóm bệnh nhân nghiên cứu. Độ tuổi trung bình trong nghiên cứu là $48,2 \pm 14,82$. Tuổi thấp nhất trong các đối tượng nghiên cứu là 13 tuổi và cao nhất là 72 tuổi. Có 7 bệnh nhân nam $(46,7 \%), 8$ bệnh nhân nữ (chiếm 53,3\%).

Phần lớn bệnh nhân trong nghiên cứu của chúng tôi $(86,7 \%)$ có triệu chứng lâm sàng khởi phát là đau đầu, ù tai, hoặc nghe thấy tiếng thổi, đây là những triệu chứng lâm sàng thuộc nhóm nhẹ. 13,3\% (2/15) có dấu hiệu tổn thương thần kinh do nhồi máu tĩnh mạch, đây là nhóm những triệu chứng lâm sàng nặng, bắt buộc phải điều trí.

4.2. Đắc điểm hình ảnh của RĐTMMC nồi sọ ngoài vùng xoang hang trên chụp mạch số hóa xóa nền

4.2.1. Số lượng dị dạng RĐTMMC. Trong 15 bệnh nhân nghiên cứu, có 13 bệnh nhân có dị dạng RĐTMMC nội sọ ngoài vùng xoang hang ở 1 vị trí, chiếm $86,7 \%$, có 2 bệnh nhân có dị dạng ở 2 vị trí khác nhau, chiếm 13,3\%. Trong đó, cả hai đều có rò ở hội lưu chẩm, trường hợp thứ nhất phối hợp với dị dạng rò xoang ngang sigma, trường hợp còn lại phối hợp với dị dạng rò ở xoang dọc trên.

4.2.2. Phân loại RĐTMMC nội sọ ngoài vừng xoang hang theo hình thái tĩnh mạch dẫn lưu (phân loại Cognard). Chúng tôi lựa chọn phân loại Cognard ${ }^{(1)}$ để phân loại RĐTMMC của các bệnh nhân trong nghiên cứu. Trong tổng số 17 dị dạng (có 2 bệnh nhân có dị dạng ở 2 vị trí như đã mô tả ở trên), có $47 \%(8 / 17)$ thuộc loại II a theo Cognard, 17,6\% (3/17) thuộc loại II $b, 29,4 \%(5 / 17)$ thuộc loại II $a+b$, và $5,9 \%$ (1/17) bệnh nhân thuộc loại thuộc loại IV. Không có bệnh nhân nào thuộc nhóm I, III và nhóm V.

Số cuống nuôi trung bình trong nghiên cứu của chúng tôi là $3.42 \pm 1.35$, ít nhất là 1 cuống, nhiều nhất là 6 cuống. Trong các nhánh mạch thuộc hệ cảnh ngoài cấp máu cho dị dạng RĐTMMC, động mạch màng não giữa chiếm tỷ lệ cao nhất $(100 \%)$, tiếp theo đó là động mạch chẩm $(88,2 \%)$, các nhánh động mạch tai sau, thái dương nông và hầu lên chiếm tỷ lệ ít (lần lượt là $35,3,23,5 \%$ và $11,8 \%$ ).

\section{3. Đánh giá quá trình can thiệp}

4.3.1. Số lân can thiệp. Có $12 / 15$ bệnh nhân $(80 \%)$ trong nghiên cứu của chúng tôi chỉ phải can thiệp 1 lần, và 3/15 bệnh nhân (20\%) phải can thiệp lần 2 .

Cả 3 bệnh nhân phải can thiệp 2 lần đều là những trường hợp dị dạng phức tạp, có nhiều cuống mạch nuôi. Đặc biệt có 1 bệnh nhân có biểu hiện lâm sàng động kinh, dị dạng phức tạp ở vị trí xoang dọc trên và hội lưu chẩm, có 6 nhánh mạch cấp máu từ cả hệ cảnh ngoài, cảnh 
trong và đốt sống. Do di dang lan tỏa và có nhiều cuống nuôi nên sau 2 lần can thiệp chỉ nút tắc được khoảng $90 \%$ dị dạng.

4.3.2. Cuống mạch can thiệp. Chúng tôi lựa chọn nhánh động mạch để can thiệp đều thuộc hệ động mạch cảnh ngoài. Trong tổng số 25 cuống nuôi được can thiệp, nhánh động mạch màng não giữa chiếm tỷ lệ cao nhất $(60 \%)$, tiếp theo là nhánh động mạch chẩm (24\%).

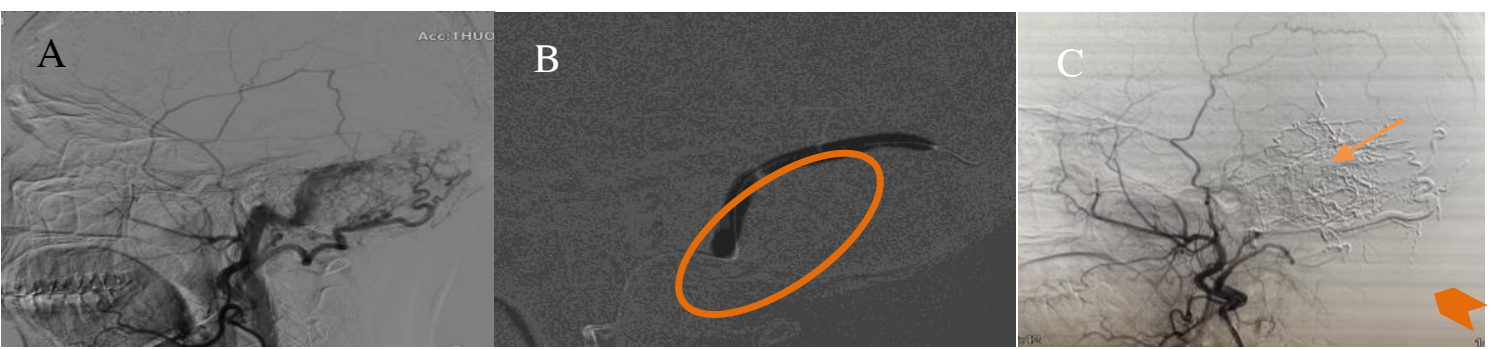

Hình 4.4. Bênh nhân can thiệp theo đường động mạch màng não giữa và đường động mạch chẩm Bệnh nhân nữ, 59 tuổi, ù tai trái, Cognard II a. (Mã lưu trữ hồ sơ I77/153)

A: cuống nuôi từ ĐM chẩm và màng não giữa thuộc ĐM cảnh ngoài.

B, C: bệnh nhân được can thiệp theo đường ĐM màng não giữa - dùng vi ống thông thường (mũi tên) và đường ĐM chẩm - dùng vi ống thông hai lòng gắn bóng (đâu mũi tên), đồng thời lên bóng chẹn bảo vệ xoang (hình elip), kết quả gây tắc hoàn toàn dị dạng.

4.3.3. Kĩ thuâtt dùng bóng chen bảo vê xoang tĩnh mạch. 15 bệnh nhân với 18 lần can thiệp có sử dụng bóng chẹn tĩnh mạch, trong đó bóng được luồn thành cổng và chẹn bao phủ trên dưới vị trí rò ở 15 trường hợp, đảm bảo khi bơm bóng chẹn không có phép Onyx tràn vào gây hẹp lòng xoang. Có 1 ca mà chiều dài bóng không thể bao phủ hết các điểm rò, do dị dạng xảy ra lan tỏa trên chiều dài xoang, buộc chúng tôi phải hạ bóng và di chuyển bóng thay đổi vị trí trong quá trình bơm, tùy theo quan sát và dự đoán hướng lan của Onyx. Hai trường hợp còn lại bóng chỉ lên tiếp cận bao phủ được một phần xoang dị dạng, do tình trạng huyết khối gây hẹp xoang và bóng không thể đưa qua được đoạn hẹp. Chúng tôi không gặp trường hợp nào dính bóng hay vỡ bóng. Kết quả bảo tồn xoang hoàn toàn trong nghiên cứu của chúng tôi đạt $83,3 \%$, bảo tồn một phần $11,1 \%$ (có trào Onyx vào trong xoang nhưng chỉ lớp mỏng, gây hẹp xoang không đáng kể).

4.4. Đánh giá mức độ tắc dị dạng RĐTMMC nội sọ ngoài vùng xoang hang ngay sau can thiệp trên chụp mạch số hóa xóa nền. Tỷ lệ tắc hoàn toàn dị dạng sau can thiệp nội mạch của chúng tôi tương đương với Feng Guo ${ }^{(5)}$, Vollherbst ${ }^{(6)}$, đây là các nghiên cứu với nhóm bệnh nhân sử dụng kĩ thuật bóng chẹn bảo vệ xoang tĩnh mạch. Các tác giả này đã trình bày một số kinh nghiệm trong quá trình bơm Onyx để đạt được kết quả tốt như sau:

Đánh giá chi tiết cấu trúc của dị dạng trên hình ảnh chup mạch (động mạch nuôi, vị trí rò, tĩnh mạch dẫn lưư).
- Can thiệp theo đường động mạch, qua nhánh động mạch màng não giữa.

- Cố gắng tiếp cận vị trí rò gần nhất có thể.

- Bơm chậm, từng đợt, đợi Onyx lan vào vị trí rò.

- Tránh trào ngược Onyx ra các nhánh lành.

4.5. Đánh giá các tai biến trong và sau can thiệp. Chúng tôi ghi nhận 4 trường hợp có tai biến nói chung, chiếm tỷ lệ $22,2 \%$ (trên tổng số lần can thiệp). Trong đó có 1 trường hợp xảy ra hiện tượng di trú Onyx vào nhánh lành của ĐM chẩm, bệnh nhân sau can thiệp có đau và sưng tấy da đầu vùng chẩm nguyên nhân do cuống mạch cấp máu cho dị dang tách ra từ thân chính động mạch chẩm. Bệnh nhân được chườm đá, liệu pháp corticoid và giảm dần các triệu chứng sau 2 tuần.

Tai biến thủng mạch do vi dây dẫn, khi cố tiếp cận nhánh xa ngoằn ngoèo của động mạch màng não giữa để đạt được vị trí gần lố rò nhất, chụp kiểm tra qua vi ống thông thấy thoát thuốc ngoại mạch, chúng tôi đã ngay lập tức thực hiện liệu pháp trung hòa heparin bằng protamin, đồng thời tiến hành bơm nhanh Onyx qua vi ống thông. Bệnh nhân sau đó được chụp CLVT, có ít máu tụ dưới màng cứng, tuy nhiên lâm sàng không có diễn biến xấu, sau 5 ngày chụp lại đã hết máu tụ.

Có hai trường hợp tai biến tràn Onyx vào xoang tĩnh mạch và tĩnh mạch vỏ não lành mất kiểm soát, ca thứ nhất là Onyx lan theo khoang giữa thành xoang và bóng, trào vào nhánh tĩnh mạch nhu mô thùy thái dương trái, sau can thiêp bệnh nhân đau đâu nhiều, chụp CHT có ổ nhồi máu vị trí tương ứng, bệnh nhân được điều trị 
dự phòng heparin và theo dõi lâm sàng, sau 1 tuần suy giảm các triệu chứng.

Ca tai biến nặng hơn đó là Onyx trào nhiều vào xoang tĩnh mạch, rồi lan tĩnh mạch vỏ não, nguyên nhân do dị dạng với nhiều điểm rò lan tỏa dọc theo xoang ngang - sigma bên trái, chiều dài bóng không đủ bao phủ phía trên và dưới các điểm rò, tuy chúng tôi đã cố gắng di chuyển bóng dự đoán theo hướng lan của Onyx để chẹn bảo vệ xoang. Dị dạng được can thiệp bít tắc hoàn toàn, tuy nhiên sau can thiệp khoảng 1 giờ, bệnh nhân xuất hiện mất tri giác và hôn mê, chụp CLVT cho thấy khối máu tụ lớn nhu mô thùy thái dương trái, bệnh nhân được mở sọ cấp cứu sau đó, chăm sóc điều trị tích cực, điểm mRs 5 sau can thiệp 3 tháng.

4.6. Đánh giá tình trạng lâm sàng của bệnh nhân sau can thiệp. Kết quả theo dõi về lâm sàng sau điều trị ít nhất 3 tháng, so sánh với lâm sàng trước khi can thiệp, tỷ lệ khỏi hoàn toàn là $53,3 \%$, giảm nhe các triệu chứng so với trước can thiệp là $26,7 \%$, có $13,3 \%$ trường hợp lâm sàng ổn định, không thây diễn biến nặng lên, và 1 trường hợp $(6,7 \%)$ là nặng hơn so với trước can thiệp. Đánh giá các bệnh nhân theo thang điểm Rankin cải tiến, phần lớn bệnh nhân $(86,7 \%)$ sau can thiệp không gặp di chứng nào (53,3\% mRs 0, 38,5\% mRs 1$)$, chỉ có 6,7\% bệnh nhân gặp di chứng vừa (mRs 2 ) và $6,7 \%$ bệnh nhân có di chứng nặng (mRs 5).

\section{KẾT LUẬN}

Kết hợp bơm bóng chẹn bảo vệ xoang tĩnh mạch với bơm Onyx đường động mạch điêu trị RĐTMMC cho kết quả điều trị tắc đường rò cao và hạn chế các tai biến

\section{TÀI LIỆ THAM KHẢO}

1. Cognard, $\mathbf{C}_{\text {., }}$ et al.. Cerebral dural arteriovenous fistulas: clinical and angiographic correlation with a revised classification of venous drainage. Radiology. 1995; 194(3): 671-680.

2. Cognard, C., et al.. Endovascular therapy and long-term results for intracranial dural arteriovenous fistulae. In: Connors JJ, Woiak JC. editors. Interventional Neuroradioloav: Strateqies and Practical Techniaues. ed 1. Philadelphia: W.B. Saunders Co.. 1999; 198-214.

3. Alturki, A. Y., Enriquez-Marulanda, A., Schmalz, P., et al.. Transarterial Onyx Embolization of Bilateral Transverse-Sigmoid Dural Arteriovenous Malformation with Transvenous Balloon Assist-Initial U.S. Experience with Copernic RC Venous Remodeling Balloon. World Neurosurgery. 2018; 109: 398-402.

4. Lu, D., Chen, L., Kang, X.. The application of Copernic RC balloon in endovascular treatment for complex intracranial dural arteriovenous fistula of the transverse-siamoid sinus. World Neurosuraerv. 2019

5. Guo, F., Zhana, Y., Liana, S., et al.. The Procedure-Related Complications of Transarterial Onvx Embolization of Dural Arteriovenous Fistula Usina Transvenous Balloon Protection. World Neurosurgery. 2018; 116: e203-e210.

6. Vollherbst, D. F., Ulfert, C., Neuberger, U., et al.Endovascular Treatment of Dural Arteriovenous Fistulas Using Transarterial Liquid Embolization in Combination with Transvenous Balloon-Assisted Protection of the Venous Sinus. American Journal of Neuroradiology. 2018; 39(7): 1296-1302

\title{
KẾT QUẢ CHỨC NĂNG SAU CẮT ĐOẠN XƯƠNG MANG BƯớU VÀ GHÉP CHỎM XƯƠNG MÁC TỰ THÂN KHÔNG Có CUỐNG MẠCH MÁU KÈM TÁI TẠO DÂY CHẰNG QUAY TRỤ DƯớI TRONG ĐIỀU TRI BƯỚU ĐẠI BÀO ĐẦU DƯỚI XƯO'NG QUAY
}

\author{
Nguyễn Văn Hiến*, Lê Chí Dũng*, Diệp Thế Hòa*, \\ Đoàn Long Vân*, Lê Văn Thọ*
}

\section{TÓM TẮT}

Mục tiêu: Đánh giá kết qữa chức năng và các biến chứng trong và sau khi phẫu thuật điều trị bướu đại bào đâu dưới xương quay (BĐ̈BĐDXQ). Đối tượng và phương pháp nghiên cứu: nghiên cứu

*Bênh viên Chấn Thương Chinhh hình, Tp.HCM

Chịu trách nhiệm chính: Nguyễn Văn Hiến

Email: bshienctch@yahoo.com.vn

Ngày nhận bài: 7.01.2021

Ngày phản biện khoa học: 5.3.2021

Ngày duyệt bài: 15.3.2021 can thiệp không nhóm chứng với cõ̃ mẫu 50 bệnh nhân ( $\geq 18$ tuổi) bị BĐBĐDXQ được phấu thuật cắt đoạn xương mang bướu, ghép chỏm xương mác tự thân không có cuống mạch, kèm tái tạo dây chằng khớp quay trụ dưới (DCKQTD) bằng gấn cơ gan tay dài tại Khoa Bệnh học Cơ Xương khớp, BV Chấn Thương Chỉnh hình TpHCM tự 1/2010-6/2020. Kết quả: Thời gian theo dõi sau phẫu thuật là $51,9 \pm 27,9$ tháng. Kết quả đo tầm độ khớp có trung bình gập là $25,9^{0}$, duỗi là $49,7^{\circ}$, nghiểng quay $12,8^{\circ}$, nghiêng trụ $29,7^{\circ}$ sấp $52,3^{\circ}$, ngửa $68,4^{\circ}$. Sức cầm nắm của tay bị bướu so với tay lành cùng bên có tỉ lệ trung bình là $70 \%$, so với tay cùng bên không bệnh là 69,9\%. Sau 